\title{
Source diagnostic and weathering indicators of oil spills utilizing bicyclic sesquiterpanes
}

\author{
WANG Chuanyuan $^{1 *}$, HU Xiaoke ${ }^{1}$, HE Shijie $^{2}$, LIU Xin ${ }^{1}$, ZHAO Mingming ${ }^{1}$ \\ ${ }^{1}$ Key Laboratory of Coastal Zone Environmental Processes, Yantai Institute of Coastal Zone Research, \\ Chinese Academy of Sciences, Yantai 264003, China \\ ${ }^{2}$ College of Geography and Planning, Ludong University, Yantai 264025, China
}

Received 20 April 2012; accepted 22 December 2012

CThe Chinese Society of Oceanography and Springer-Verlag Berlin Heidelberg 2013

\begin{abstract}
Bicyclic Sesquiterpanes (BSs) are ubiquitous components of crude oils and ancient sediments. BSs in crude oils and diesel oil were identified and characterized, the effects of moderate weathering on BS distributions were discussed, and a methodology using diagnostic indices of BSs was developed for oil correlation and differentiation. The results showed that crude oils and oil products had different abundances and distributions of BSs and, consequently, resulted in different diagnostic ratios. The selected diagnostic ratio indices of BSs, such as BS4/BS5 (ratio of 4,4,8,9,9-pentamethyl-decahydronaphthalene to $8 \beta(\mathrm{H})$-drimane), BS6/BS5 (ratio of 4,4,9,9,10-pentamethyl-decahydronaphthalene to $8 \beta(\mathrm{H})$-drimane), BS8/BS9 (ratio of the second peak to the third peak of $\mathrm{C}_{16}$ sequiterpane), and BS8/BS10 (ratio of $\mathrm{C}_{16}$ sequiterpane to $8 \beta(\mathrm{H})$-homodrimane), still maintained better stabilities (\%RSD <5\%) after weathering for $30 \mathrm{~d}$. The longer weathering process $(150 \mathrm{~d})$ had some effect on such ratios $(5 \%<\%$ RSD $<10 \%)$. The facts of the uniqueness, abundance in petroleum, and chemical stability of BSs enable them to be suitable as an effective diagnostic means for identifying spilled oil with moderate weathering, particularly for lighter refined product samples that are difficult to identify by current techniques.
\end{abstract}

Key words: bicyclic sesquiterpanes, distribution, diagnostic indices, weathering, oil spill source identification

Citation: Wang Chuanyuan, Hu Xiaoke, He Shijie, Liu Xin, Zhao Mingming. 2013. Source diagnostic and weathering indicators of oil spills utilizing bicyclic sesquiterpanes. Acta Oceanologica Sinica, 32(8): 79-84, doi: 10.1007/s13131-013-0344-y

\section{Introduction}

At present, China is the fifth largest oil producer and the second largest oil consumer in the world. There is now a greater chance that oil spill accidents will occur during the transportation of crude oils and oil products, placing the Chinese marine environment at risk. According to correlative statistic data, oil spills from various ships resulted in a total of 2635 accidents offshore of China between 1973 and 2006. Oil spills can cause extensive damage to marine and terrestrial life, human health, and natural resources. Therefore, characterization of chemical compositions and identi?cation of oil spill sources are, in many cases, critical for providing forensic evidence in the investigation of oil spill accidents and settling disputes related to liability (Wang and Fingas, 2003).

The biomarkers most commonly used in forensic investigations are the high molecular weight tri- and pentacyclic terpanes and steranes (Prince et al., 2002; Hegazi et al., 2004; Garcia and Grimalt, 2006). However, pentacyclic triterpanes and steranes, with high boiling points, are generally absent or in very low abundances in lighter petroleum products such as jet fuels and mid-range diesels. For lighter petroleum products, refining processes have removed most high molecular weight biomarkers from the corresponding crude oil feed stocks, while the smaller compounds of bicyclic sesquiterpanes (BSs) are greatly concentrated in these petroleum products
(Wang et al., 2005). BSs are commonly found in crude oils, intermediate petroleum distillates, and finished petroleum products (Yang et al., 2009). Although numerous studies on applications of BSs have been reported, they mostly relied on the qualitative information of BSs for geological application (Zhang et al., 2002). There is no single fingerprinting technique that is a definitive and ultimately defensible forensic criterion. Therefore, a "multicriteria" approach—characterization of more than one suite of analyses-for spill source identification is necessary.

Once oil has been spilled into the environment, it is subjected to a variety of weathering processes, including evaporation, dissolution, photochemical oxidation, and microbial biodegradation (Garrett et al., 1998; Barakat et al., 2002; Wang and Fingas, 2003; D'Auria et al., 2009). The combined effects of weathering can strongly modify the fingerprints and parameters used to correlate the oil sample with its source on the basis of gas chromatograph (GC) and gas chromatograph-mass spectrometer (GC-MS) analysis. Therefore, it is also very important to understand the relationships between the weathering processes and the distribution of BSs. In the short term after a spill, evaporation is the single most important and dominant weathering process (Wang et al., 2011). Previous studies indicated that evaporation had no significant effect on the distribution of BSs (Wang et al., 2005; Yang et al., 2009). For example, the effects of evaporative weathering on sesquiterpane distributions

Foundation item: Key Projects in the Yantai Science \& Technology Pillar Program under contract No. 2011060; the National Natural Science Foundation of China under contract Nos 40806048 and 41206089; Hundred Talents Program of Chinese Academy of Sciences.

*Corresponding author, E-mail: cywang@yic.ac.cn 
were examined (Wang et al., 2005). However, little work has been done to evaluate the effect of moderate or high weathering on the distribution of BSs for oil spill identification under different weathering processes.

In this work, the distributions of BSs in crude oils and diesel fuel derived from China were identified and characterized. Weathering effects on BSs distribution were quantitatively studied and a number of diagnostic indices of BSs were developed for oil correlation and differentiation.

\section{Experimental design}

\subsection{Weathering simulation experiment}

A simplified weathering simulation experiment was performed on the representative crude oils and diesel fuel. Crude oil is derived from Liaohe Oilfields, China. Based on the previous study results, no or only trace amounts of sesquiterpane were detected in gasoline, light kerosene, and heavy-end lubricating oils (Yang et al., 2009). Thus, diesel fuel was regarded as a typical petroleum product in this study. For the weathering experiment outdoors, the weighed crude oil samples (LH-W, C-W, about $40 \mathrm{mg}$ each) were dropped into a series of $250 \mathrm{ml}$ beakers containing purified sea water (salinity of 32 ), which spread rapidly to form slicks on the surface. Beakers were placed on a window sill of the laboratory building for $150 \mathrm{~d}$. For the laboratory experiments, similar samples (LH-N, C-N) were placed in a ventilating cabinet, stirred by magnetic stirrers in the presence of wind at $3 \mathrm{~m} / \mathrm{s}$, under irradiation with incandescent and fluorescent lamps (luminance was about $2300 \mathrm{~lx}$ ) at room temperature (thermostatic bath held at $20^{\circ} \mathrm{C}$ ) for $150 \mathrm{~d}$. Thus, the main weathering processes (evaporation, photo oxidation, and biodegradation) were artificially reproduced in the laboratory. The biodegradation process in this paper only means the hydrocarbon biodegradation activities of marine bacteria under the natural environment.

\subsection{Separation and analysis}

The oil samples were deasphalted by precipitation with $n$-hexane followed by filtration. The deasphalted oil was fractionated by column chromatography on alumina over silica gel. Saturated hydrocarbons, aromatic hydrocarbons, and nonhydrocarbons were obtained by successively eluting with $n$ hexane, toluene, and chloroform/methanol (v/v, 98:2), respectively.

The saturated hydrocarbon fraction was used for analysis of BS, terpane, and sterane compounds as well as $n$ alkanes. The saturated hydrocarbons were analyzed with a $6890 \mathrm{~N}$ GC/5973N mass spectrometer equipped with a HP-5 capillary column $(50 \mathrm{~m} \times 0.32 \mathrm{~mm} \times 0.25 \mu \mathrm{m}$, Agilent Technologies, USA). The GC oven temperature was programmed from $80^{\circ} \mathrm{C}$ to $300^{\circ} \mathrm{C}$ at $4^{\circ} \mathrm{C} / \mathrm{min}$, and maintained at this temperature for $30 \mathrm{~min}$. Helium was used as a carrier gas. Mass spectrometer conditions were electron ionization at $70 \mathrm{eV}$ with an ion source temperature at $250^{\circ} \mathrm{C}$.

\section{Results and discussion}

\subsection{Distribution of BSs in crude oils and diesel fuel from China}

The BSs eluted between $n$ - $\mathrm{C}_{13}$ and $n-\mathrm{C}_{16}$ (boiling points: $235-287^{\circ} \mathrm{C}$ ), while the conventional polycyclic terpanes and steranes eluted between $n-C_{21}$ and $n-C_{37}$ (boiling points: $345-$ $500^{\circ} \mathrm{C}$ ). Analysis of BSs will provide another criterion to fingerprint oil sands in addition to polycyclic aromatic hydrocarbons (PAHs) and biomarkers (Wang et al., 2005; Stout et al., 2005). The identified BSs in this study are illustrated in Fig. 1. Their relevant information, such as abbreviations and retention indices, are summarized in Table 1 . Ten major peaks were identified at $\mathrm{m} / \mathrm{z} 123$ as drimane-based $\mathrm{C}_{14}$ (BS1 and BS2), $\mathrm{C}_{15}$ (BS3 to BS6), and $\mathrm{C}_{16}$ (BS7 to BS10) BSs with molecular weights of 194, 208, and 222 atomic mass units, respectively. The overall distribution patterns of individual sesquiterpane compounds in diesel fuels were similar to that in crude oils: BS3, BS5, and BS10 were the most dominant while BS9 often showed the lowest abundance. There were distinguishing features on the relative distribution patterns of BSs in crude oils from different sources. Thus, the fingerprints of BSs as well as their diagnostic ratios may find their forensic applications for oil source identification.

BSs in most crude oils and diesel fuels were dominated by $8 \beta(\mathrm{H})$-drimane and $8 \beta(\mathrm{H})$-homodrimane (compounds $\mathrm{B}$ S5 and BS10, respectively) (Fig. 1), although these compound$\mathrm{s}$ were present in varying proportions. The ratio of $8 \beta(\mathrm{H})$ drimane $/(8 \beta(\mathrm{H})$-drimane $+8 \beta(\mathrm{H})$-homodrimane) varied from $0.30-0.55$ in the crude oils studied (ratio: BS5/[BS5+BS10]; Table 2). For crude oil, this particular ratio has been suggested to be related to the depositional environment of the oil source rock (Weston et al., 1989). The Pristane/Phytane ratio (Pr/Ph) is dependent upon the source of organic matter and diagenetic transformations. The $\mathrm{Pr} / \mathrm{Ph}$ ratio is widely invoked as an indicator of the redox condition in the depositional environment (Peters and Moldowan, 1993). Figure 2 depicts the cross plots of $\mathrm{Pr} / \mathrm{Ph}$ versus BS4/BS5, $\mathrm{Pr} / \mathrm{Ph}$ versus BS6/BS5, $\mathrm{Pr} / \mathrm{Ph}$ versus $\mathrm{B}-$ S8/BS10, and $\mathrm{Pr} / \mathrm{Ph}$ versus BS5/BS5+BS10 for oil samples from different regions. There was a large scatter in the cross plot data: $\mathrm{Pr} / \mathrm{Ph}, \mathrm{BS} 4 / \mathrm{BS} 5, \mathrm{BS} 6 / \mathrm{BS} 5, \mathrm{BS} 8 / \mathrm{BS} 10$, and BS5/(BS5+BS10). Thus, the variability in the BS4/BS5, BS6/BS5, BS8/BS10, and BS5/(BS10+BS5) ratios observed among the oil samples may reflect variability in the character of the parent crude oil(s). Moreover, the considerable variability that exists among the dispensed diesel fuels studied was shown by other ratios among BSs (Table 2). The selection of these particular ratios was based

Table 1. Bicyclic sesquiterpanes identified in oil samples by GC-MS

\begin{tabular}{|c|c|c|c|c|c|}
\hline Peak number & Compound & Abbreviation & Formula & $\mathrm{M}^{+}(\mathrm{m} / \mathrm{z})$ & Base peak \\
\hline 1 & 4,4,8,10-tetramethyl-decahydronaphthalene & BS1 & $\mathrm{C}_{14} \mathrm{H}_{26}$ & 194 & 179 \\
\hline 2 & nordrimane & BS2 & $\mathrm{C}_{14} \mathrm{H}_{26}$ & 194 & 179 \\
\hline 3 & 4,4,8,8,9-pentamethyl-decahydronaphthalene & BS3 & $\mathrm{C}_{15} \mathrm{H} 28$ & 208 & 193 \\
\hline 4 & 4,4,8,9,9-pentamethyl-decahydronaphthalene & BS4 & $\mathrm{C}_{15} \mathrm{H}_{28}$ & 208 & 193 \\
\hline 5 & $8 \beta(\mathrm{H})$-drimane & BS5 & $\mathrm{C}_{15} \mathrm{H}_{28}$ & 208 & 123 \\
\hline 6 & $4,4,9,9,10$-pentamethyl-decahydronaphthalene & BS6 & $\mathrm{C}_{15} \mathrm{H}_{28}$ & 208 & 123 \\
\hline 7 & $\mathrm{C}_{16}$ sequiterpane & BS7 & $\mathrm{C}_{16} \mathrm{H}_{30}$ & 222 & 123 \\
\hline 8 & $\mathrm{C}_{16}$ sequiterpane & BS8 & $\mathrm{C}_{16} \mathrm{H}_{30}$ & 222 & 193 \\
\hline 9 & $\mathrm{C}_{16}$ sequiterpane & BS9 & $\mathrm{C}_{16} \mathrm{H}_{30}$ & 222 & 193 \\
\hline 10 & $8 \beta(\mathrm{H})$-homodrimane & BS10 & $\mathrm{C}_{16} \mathrm{H}_{30}$ & 222 & 123 \\
\hline
\end{tabular}



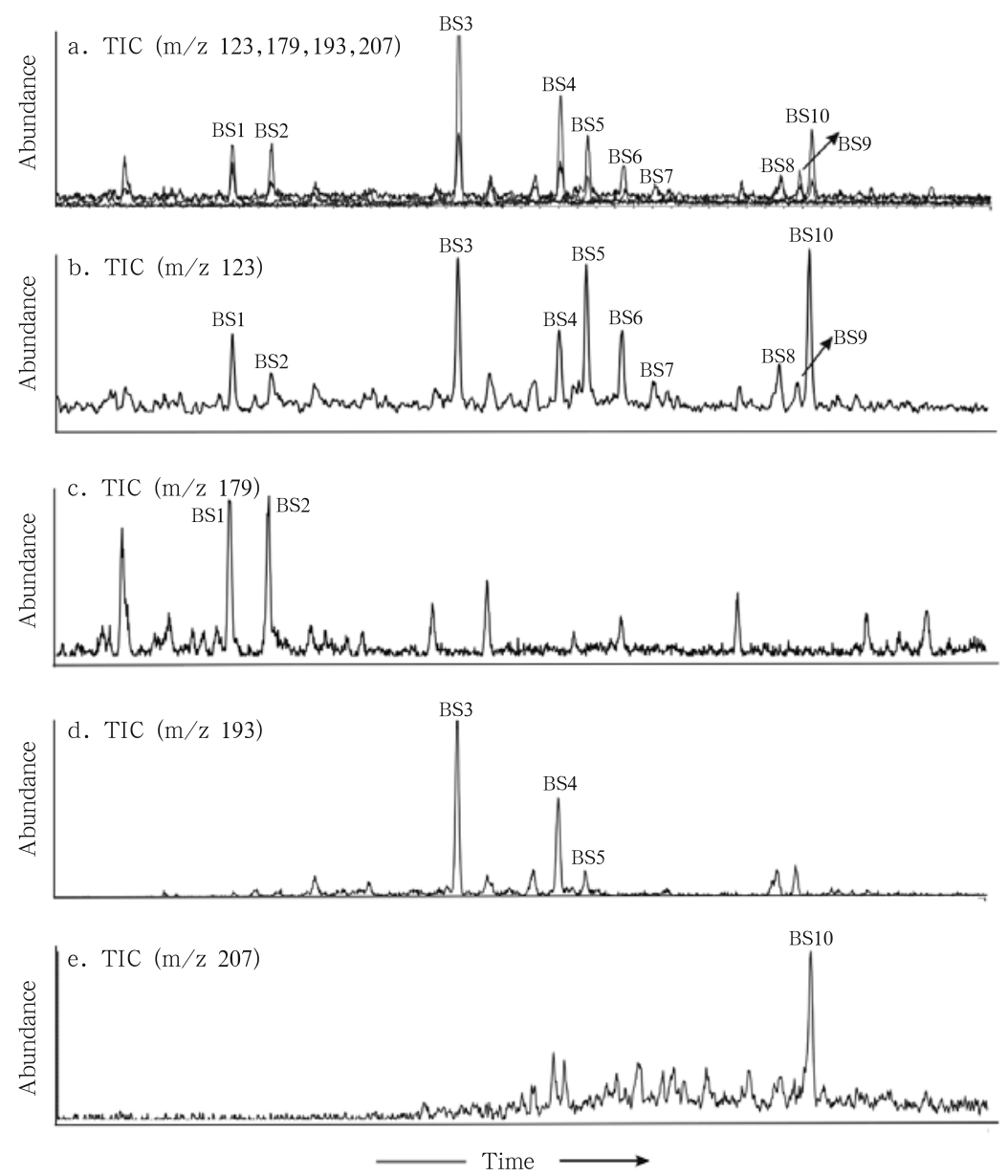

Fig.1. GC-MS chromatograms of bicyclic sesquiterpanes in the crude oil from Liaohe Oilfield: $a$. total ion chromatogram, b. $\mathrm{m} / \mathrm{z}$ 123, c. m/z 179, d. m/z 193, and e. m/z 207 chromatograms.

upon our observations of the data, the objective of which was to evaluate whether distillate fuels collected from different locations and/or times (i.e., different sources) exhibited different BS distributions.

The diagnostic ratios of selected paired BSs in crude oils from some oilfields in China were developed and calculated. Diagnostic ratios varied greatly among oils from different regions. The cross plot of peak 4/peak 5 (P4:P5) versus peak 3/peak 5 (P3:P5), peak 4/peak 5 (P4:P5) versus peak 6/peak 5 (P6:P5), and peak 4/peak 5 (P4:P5) versus peak 8/peak 10 (P8:P10) are shown in Fig. 3. There was also a large scatter in this set of oils in these cross plot data. This implies that the BS ratios, in combination with other fingerprinting data, may be used to discriminate different oils and identify the source of spill samples.

\subsection{Effects of weathering on BSs distributions}

The second step was to determine if moderately or highly weathered processes can compromise correlations between pollutants and suspected sources. This work quantitatively investigated the effects of weathering on alteration of BS distributions and their relative diagnostic ratios. Table 2 summarizes the relative abundance of BSs and chemical composition change of selected hydrocarbon groups in crude oil and diesel fuels at different degrees of weathering. As shown in Table 2, the weathering process had little effect on distribution patterns of BSs. No apparent depletion was observed for BSs in the studied oil samples. However, it was found that the smaller $\mathrm{C}_{14} \mathrm{BSs}$ (BS1 and BS2) started to be lost as oil was subjected to a higher degree of weathering. Stout et al. (2005) also reported that, if evaporation continued and had affected the $n$-alkanes beyond $n-\mathrm{C}_{13}$, then a relative depletion of the lower boiling $\mathrm{C}_{14} \mathrm{H}_{26}$ BSs would be expected. For highly weathered oil in this study, however, the lighter $\mathrm{C}_{14}$ BSs, Peaks 1 and 2, were preferentially lost.

We also investigated the molecular ratios of BSs in fresh and weathered oils (Table 2). For lightly and some moderately weathered oils, most of these diagnostic ratios provide a useful tool for spill identification. However, for heavily weathered samples, the early-eluted lower molecular weight $\mathrm{C}_{14} \mathrm{BSs}$ (BS1 and BS2) could be preferentially depleted into certain degrees, resulting in some changes of their corresponding diagnostic ratios, such as BS1/BS5, BS1/BS10, and (BS1+BS2)/BS10. 4,4,8,8,9-pentamethyl-decahydronaphthalene and 4,4,8,9,9-pentamethyl-decahydronaphthalene are rearranged isomers of $8 \beta(\mathrm{H})$-drimane. It has been reported that the relative amount of the rearranged drimane in terrestrial facies oils is higher than that of marine facies oils (Zhang et al., 2002). The (BS3+BS4)/BS5 ratio, invoked as an indicator of the redox condition in the depositional environment, also decreased. Such change is likely due to the more ready degradation of the 
Table 2. Weathering regularities of sesquiterpanes from crude oil and diesel fuel

\begin{tabular}{|c|c|c|c|c|c|c|c|c|c|c|c|c|}
\hline Sample No. & Time/d & BS1/BS2 & BS1/BS5 & $\mathrm{BS} 1 / \mathrm{BS} 10$ & BS3/BS4 & BS3/BS5 & BS4/BS5 & BS6/BS5 & BS8/BS9 & BS3/BS10 & BS5/BS10 & BS8/BS10 \\
\hline $\mathrm{C}-0$ & 0 & 2.02 & 0.59 & 0.52 & 1.84 & 1.06 & 0.58 & 0.53 & 1.42 & 70.94 & 0.88 & 0.31 \\
\hline $\mathrm{C}-\mathrm{N}-1$ & 10 & 2.03 & 0.46 & 0.42 & 1.89 & 1.05 & 0.55 & 0.54 & 1.28 & 0.95 & 0.91 & 0.28 \\
\hline $\mathrm{C}-\mathrm{N}-2$ & 20 & 2.06 & 0.42 & 0.36 & 2.11 & 1.12 & 0.53 & 0.53 & 1.57 & 0.96 & 0.85 & 0.28 \\
\hline $\mathrm{C}-\mathrm{N}-3$ & 30 & 1.86 & 0.35 & 0.31 & 1.94 & 1.00 & 0.52 & 0.53 & 1.29 & 0.89 & 0.89 & 0.28 \\
\hline $\mathrm{C}-\mathrm{N}-4$ & 150 & 1.15 & 0.02 & - & 1.01 & 0.54 & 0.53 & 0.76 & 1.42 & 0.19 & 0.35 & 0.28 \\
\hline${ }^{a} \mathrm{RSD}_{1}$ & & 3.79 & 16.54 & 16.34 & 4.98 & 3.84 & 4.24 & 0.63 & 4.93 & 2.74 & 2.24 & 3.85 \\
\hline${ }^{b} \mathrm{RSD}_{2}$ & & 18.89 & 51.75 & 54.31 & 22.0 & 22.2 & 4.04 & 6.7 & 7.64 & 38.02 & 27.34 & 3.71 \\
\hline $\mathrm{C}-0$ & 0 & 2.02 & 0.59 & 0.52 & 1.84 & 1.06 & 0.58 & 0.53 & 1.42 & 0.94 & 0.88 & 0.31 \\
\hline C-W-1 & 10 & 1.78 & 0.5 & 0.47 & 2.09 & 1.19 & 0.57 & 0.56 & 1.61 & 1.12 & 0.95 & 0.31 \\
\hline C-W-2 & 20 & 1.32 & 0.5 & 0.4 & 1.83 & 1.00 & 0.54 & 0.67 & 1.24 & 0.8 & 0.81 & 0.3 \\
\hline C-W-3 & 30 & 1.32 & 0.5 & 0.4 & 1.83 & 1.00 & 0.54 & 0.67 & 1.24 & 0.8 & 0.81 & 0.3 \\
\hline C-W-4 & 150 & 0.81 & 0.05 & 0.02 & 1.27 & 0.67 & 0.53 & 0.66 & 1.42 & 0.3 & 0.46 & 0.3 \\
\hline${ }^{\mathrm{c}} \mathrm{RSD}_{3}$ & & 15.86 & 7.2 & 10.01 & 5.51 & 7.02 & 2.76 & 4.63 & 3.11 & 12.82 & 6.37 & 2.48 \\
\hline${ }^{\mathrm{d}} \mathrm{RSD}_{4}$ & & 28.9 & 45.16 & 48.55 & 15.25 & 17.57 & 3.49 & 10.01 & 9.97 & 34.23 & 21.76 & 2.34 \\
\hline LH-0 & 0 & 1.53 & 0.26 & 0.20 & 1.45 & 0.73 & 0.51 & 0.46 & 1.61 & 0.59 & 0.80 & 0.30 \\
\hline LH-N-3 & 30 & 1.01 & 0.07 & 0.04 & 1.06 & 0.47 & 0.44 & 0.46 & 1.68 & 0.28 & 0.60 & 0.31 \\
\hline LH-N-4 & 150 & 1.93 & 0.17 & 0.08 & 1.04 & 0.37 & 0.36 & 0.42 & 1.56 & 0.17 & 0.45 & 0.24 \\
\hline${ }^{\mathrm{e}} \mathrm{RSD}_{5}$ & & 20.3 & 58.12 & 66.78 & 15.7 & 22.1 & 4.62 & 0.35 & 2.21 & 35.16 & 14.16 & 0.77 \\
\hline${ }^{\mathrm{f}} \mathrm{RSD}_{6}$ & & 30.8 & 56.94 & 79.77 & 19.6 & 35.6 & 17.1 & 5.45 & 3.76 & 62.73 & 28.45 & 9.56 \\
\hline LH-W-0 & 0 & 1.53 & 0.26 & 0.20 & 1.45 & 0.73 & 0.51 & 0.46 & 1.61 & 0.59 & 0.80 & 0.30 \\
\hline LH-W-3 & 30 & 1.11 & 0.09 & 0.05 & 1.15 & 0.51 & 0.45 & 0.44 & 1.61 & 0.29 & 0.57 & 0.30 \\
\hline LH-W-4 & 150 & 1.19 & 0.32 & 0.33 & 1.82 & 0.78 & 0.43 & 0.40 & 1.27 & 0.79 & 1.02 & 0.36 \\
\hline${ }^{\mathrm{g}} \mathrm{RSD}_{7}$ & & 15.9 & 46.56 & 58.67 & 11.6 & 17.6 & 4.85 & 1.86 & 0.06 & 33.29 & 16.67 & 0.87 \\
\hline${ }^{\mathrm{h}} \mathrm{RSD}_{8}$ & & 17.4 & 52.86 & 70.78 & 22.7 & 20.9 & 8.70 & 7.53 & 13.3 & 45.07 & 28.12 & 9.49 \\
\hline
\end{tabular}

Notes: - means not detected due to low abundance; a relative standard deviation among C-0, C-N-1, C-N-2, and C-N-3; ${ }^{b}$ relative standard deviation among $\mathrm{C}-0, \mathrm{C}-\mathrm{N}-1, \mathrm{C}-\mathrm{N}-2, \mathrm{C}-\mathrm{N}-3$, and $\mathrm{C}-\mathrm{N}-4$; ${ }^{\mathrm{c}}$ relative standard deviation among C-0, C-W-1, C-W-2, and C-W-3; ${ }^{\mathrm{d}}$ relative standard

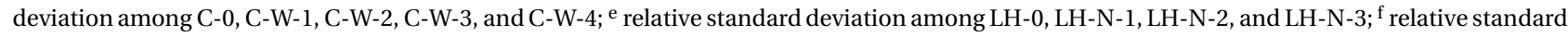
deviation among LH-0, LH-N-1, LH-N-2, LH-N-3, and LH-N-4; g relative standard deviation among LH-0, LH-W-1, LH-W-2, and LH-W-3; and $\mathrm{h}$ relative standard deviation among LH-0, LH-W-1, LH-W-2, LH-W-3, and LH-W-4.
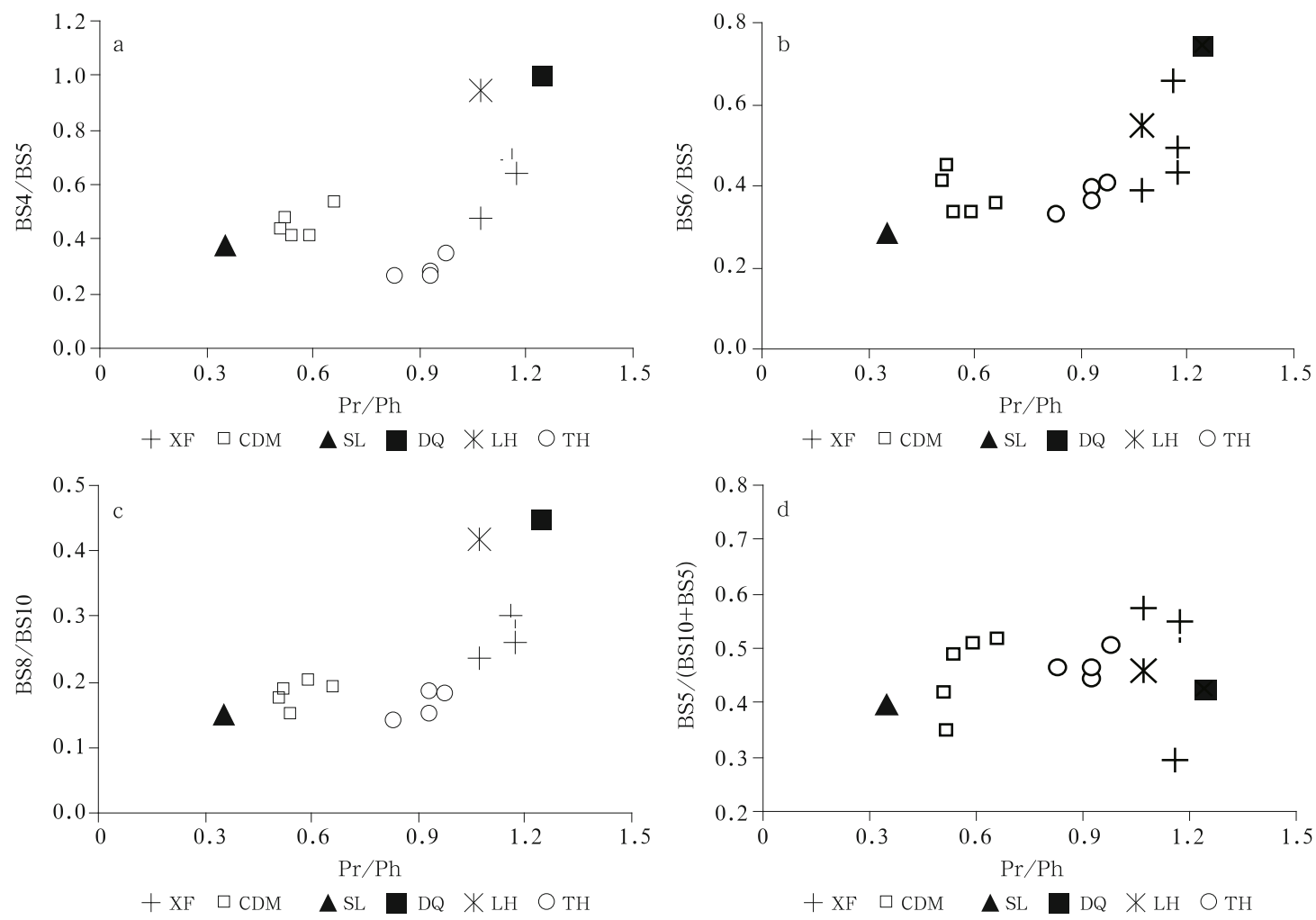

Fig.2. Relationships between Pr/Ph and BS4/BS5 (a), between Pr/Ph and BS6/BS5 (b), between Pr/Ph and BS8/BS10 (c), and between $\mathrm{Pr} / \mathrm{Ph}$ and BS5/(BS10+BS5) (d). XF represents crude oils from Xifeng Oilfield, CDM crude oils from Qaidam Basin, SL crude oils from Shengli Oilfield, DQ crude oils from Daqing Oilfield, LH crude oils from Liaohe Oilfield, and TH crude oils from Tahe Oilfields. 

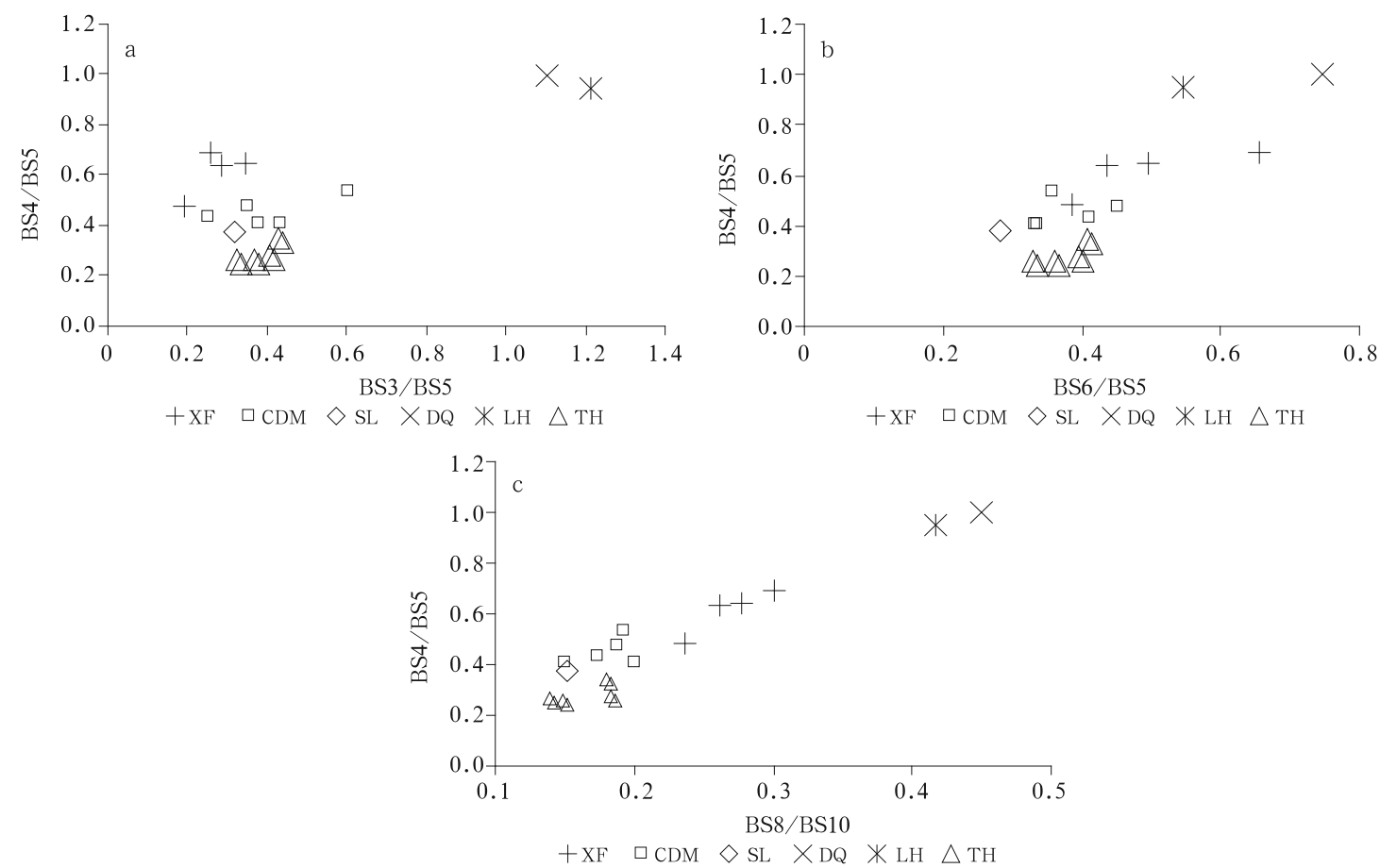

Fig.3. Cross plots of P4:P5 versus P3:P5 (a), P4:P5 versus P6:P5 (b), and P4:P5 versus P8:P10 (c).

rearranged isomer of $8 \beta(\mathrm{H})$-drimane than $8 \beta(\mathrm{H})$-drimane.

Based on the evaluation method of indices suggested by Stout (2001) and Li (2009), relative standard deviation (\%RSD) was considered as an indicator to evaluate the variability of diagnostic indices in this experiment. The indices with \%RSD < $5 \%$ were probably not affected by weathering, while a $\%$ RSD more than $10 \%$ suggests that weathering had a remarkable effect on the index. It was shown that the selected diagnostic ratios of BSs, such as BS4/BS5, BS6/BS5, BS8/BS9, and BS8/BS10, still maintained better stabilities (\%RSD $<5 \%$ ) after weathering for $30 \mathrm{~d}$. Furthermore, the longer weathering process (150 d) had some effect on the ratios $(5 \%<\%$ RSD $<10 \%)$. Moreover, the weathering level of samples in laboratory experiments was lower than that of experiments outdoors.

As mentioned above, BSs retained their molecular compositions during the weathering process of moderate degradation and could be used in tracking sources of hydrocarbon pollution in the marine environment. However, it should be noted that in severely weathered or long-term weathered oil, the degradation of biomarkers, especially $\mathrm{C}_{14}$ BSs, was also observed.

\section{Conclusions}

Abundances and distributions of BSs in crude oils were notably different from those of oil products, and consequently, resulted in different diagnostic ratios. BSs retained their molecular compositions during the weathering process of moderate degradation and could be used in tracking the origin and sources of hydrocarbon pollution in the marine environment. The selected diagnostic ratio indices of BSs, such as BS4/BS5, BS6/BS5, BS8/BS9, and BS8/BS10, still maintained better stabilities (\%RSD $<5 \%$ ) after weathering for $30 \mathrm{~d}$. The longer weathering process $(150 \mathrm{~d})$ had some effect on the ratios $(5 \%<\%$ RS$\mathrm{D}<10 \%$ ). These diagnostic indices can be used for the identification of oil source, which may offer potential applications for oil spill identification in cases where the tri- to pentacyclic biomarkers are absent due to refining or environmental weathering of oils. Sesquiterpanes can markedly improve confidence in oil spill identification, especially for lighter petroleum products.

\section{References}

Barakat A O, Mostafa A R, Qian Y, et al. 2002. Application of petroleum hydrocarbon chemical fingerprinting in oil spill investigationsgulf of Suez, Egypt. Spill Sci Technol Bull, 7(5-6): 229-231

D’Auria M, Emanuele L, Racioppi R, et al. 2009. Photochemical degradation of crude oil: Comparison between direct irradiation, photocatalysis, and photocatalysis on zeolite. J Hazard Mater, 164(1): 32-38

Garrett R M, Pickering I J, Haith C E, et al. 1998. Photooxidation of crude oils. Environ Sci Technol, 32(23): 3719-3723

Garcia O T, Grimalt J O. 2006. GC and GC-MS characterization of crude oil transformation in sediments and microbial mat samples after the 1991 oil spill in the Saudi Arabian Gulf coast. Environ Pollut, 139(3): 523-531

Hegazi A H, Anderson J T, Abu-Elgheit M A, et al. 2004. Source diagnostic and weathering indicators of tar-balls utilizing acyclic, polycyclic and S-heterocyclic components. Chemosphere, 55(7): 1051-1065

Li Yun, Xiong Yongqiang, Yang Wanying, et al. 2009. Compoundspecific stable carbon isotopic composition of petroleum hydrocarbons as a tool for tracing the source of oil spills. Mar Pollut Bull, 58(1): 114-117

Peters K E, Moldowan J M. 1993. The Biomarker Guide. Interpreting Molecular Fossils in Petroleum and Ancient Sediments. Englewood Cliffs, NJ: Prentice-Hall

Prince R C, Owens E H, Sergy G A. 2002. Weathering of an Arctic oil spill over 20 years: the BIOS experiment revisited. Mar Pollut Bull, 44(1): 1236-1242

Stout S A, Uhler A D, McCarthy K J. 2001. A strategy and methodology for defensibly correlating spilled oil to source candidates. Environ Fore, 2: 87-98

Stout S A, Uhler A D, McCarthy K J. 2005. Middle distillate fuel fingerprinting using drimane-based bicyclic sesquiterpanes. Environ Forensics, 6(3): 241-251 
Wang Zhendi, Fingas M F. 2003. Development of oil hydrocarbon fingerprinting and techniques. Mar Pollut Bull, 47(9-12): 423-452

Wang Zhendi, Yang Chun, Fingas M, et al. 2005. Characterization, weathering, and application of sesquiterpanes to source identification of spilled petroleum products. Environ Sci Technol, 39(22): 8700-8707

Wang Chuanyuan, Du Jianguo, Gao Xuelu, et al. 2011. Chemical characterization of naturally weathered oil residues in the sedimen from Yellow River Delta, China. Marine Pollution Bulletin, 62(1): 2469-2475
Weston R J, Philp R P, Sheppard C M, et al. 1989. Sesquiterpanes, diterpanes, and other higher terpanes in oils from the Taranaki Basin of New Zealand. Org Geochem, 14(4): 405-421

Yang Chun, Wang Zhendi, Hollebone B P, et al. 2009. Characteristics of bicyclic sesquiterpanes in crude oils and petroleum products. J Chromatogr A, 1216(20): 4475-4484

Zhang Chunming, Guo Kangliang, Zhang Jun, et al. 2002. Distribution characteristics and their geochemical significance of bicyclic sesquiterpanes. J Jianghan Pet Inst, 24(2): 30-32 